\title{
An Imperative Note on Novel Drug Delivery Systems
}

\author{
Vijaya Shanti Bheemidi ${ }^{1 *}$, Mrudula Tiruckovela ${ }^{1}$ and PavanKumar Varanasi ${ }^{2}$
}

${ }^{1}$ Department of Biotechnology, Nottingham Trent University, Nottingham, United Kingdom

${ }^{2}$ Department of Molecular Cell Biology, Nottingham Trent University, Nottingham, United Kingdom

\begin{abstract}
A new era of science and technology has evolved in pharmaceutical research focussed at development of different novel drug delivery systems. The evolution of an existing drug from its traditional form to a novel delivery system may considerably improve its performance in aspects of efficacy, safety and patient compliance. So the method of administrating a drug can also have significant effect in its efficacy. In recent years the considerable advances in drug delivery systems have enabled more effective routes of administration. This review highlights the different novel drug delivery system, drug carriers and their potential to resolve the current challenges faced by biotechnology and pharmaceutical Industries.
\end{abstract}

Keywords: Nanoparticles; Carriers; Drug delivery; Hydrogels

\section{Introduction}

Most of the pharmaceutical companies for their industrial existence have primarily consisted of fast reacting and simple chemical compounds that are taken in different forms such as solid pills, injections, paste, ointments etc., [1] but during the past three decades a new era of science and technology has evolved in pharmaceutical research focussed at development of different novel drug delivery systems $[2,3]$. The process of delivering a pharmaceutical compound to achieve a significant therapeutic effect in an efficient manner can be defined as novel drug delivery system [4]. The evolution of an existing drug from its traditional form to a novel delivery system may considerably improve its performance in aspects of efficacy, safety and patient compliance [5].

Drug characteristics differ dramatically depending upon its size, chemical composition, hydrophilicity and potency to identify the molecules, even though they are aimed to treat the same symptoms. The result of drug activity is nothing but the molecular interactions in certain cells $[1,6-8]$. Some drugs possess an accomplished concentration range within where the maximum benefit is derived and the concentration levels above or below this range can lead to toxic effect or no therapeutic effect produced at all [4,9-11]. So the method of administrating a drug can also have significant effect in its efficacy. Therefore it is very necessary for the drug to "deliver at the right place, at the right concentration for the right period of time" $[1,12]$. These aspects suggested a growing need for multidisciplinary approaches to deliver the drugs to their target tissues. The new strategies like controlling the pharmacokinetics, immunogenicity, bio recognition, pharmacodynamics, non-specific activity and efficacy of drugs were generated which were based on the interdisciplinary approaches like integration of pharmaceutics, polymer science, molecular biology and bio conjugate chemistry. In order to increase the therapeutic effects of drugs, simultaneously to minimize their side effects different drug delivery systems were designed [4,13-15].

\section{Novel Drug Delivery Systems}

In the $21^{\text {st }}$ century a scenario raised where the pharmaceutical companies caught between the reducing prices of existing drugs and increasing cost for successful drug discovery and its development. The average cost and time for a new drug discovery and its development are much higher (approximately $\$ 500$ million and $10-12$ years) than compared to development of novel drug delivery systems (NDDS) (\$20-
50 million and 3-4 years). Due to patent expiry with subsequent entry of generic competition and limited formularies the entire pharmaceutical companies approximately (350 drug delivery companies and 1000 medical device companies) concentrated on developing and designing new drug delivery systems [5,16-17]. The significant improvements in clinical efficacy, patient compliance, extension of product life through control release formulations as well as economic considerations such as reduced frequency and cost of the administering the drug are driving the demand for high performance, versatility and controlled-release systems [18-19]. This made the novel drug delivery systems as one of the fastest growing segment in the pharmaceutical companies [20]. The global market for advanced drug delivery systems was more than $\$ 75$ billion in 2005 and mounted to $\$ 139$ billion in 2009.It was estimated to increase $\$ 196.4$ billion for a compound annual growth rate (CAGR) of $7.2 \%$ in the 5 -year period. Targeted drug delivery which reached $\$ 50.9$ billion in 2009 and is expected to $\$ 80.2$ billion in 2014 for a CAGR of $9.5 \%$., whereas sustained release products reached $\$ 36.1$ billion in 2009 and expected to $\$ 45.8$ billion in 2014 for a CAGR of $4.9 \%$. There is a rapid development within this market preferably in the area of alternatives to injected macromolecules, peptide drugs, genetically engineered proteins and other biological therapeutics [21,22].

\section{Site Directed Drug Carrying Vehicles / Drug Carriers}

In recent years the considerable advances in drug delivery systems have enabled more effective routes of administration. To deliver the drugs to their specific target tissues, drug carriers (the substances which play crucial role in significant delivery and effectiveness of drugs) are used [23]. A wide range of organic systems like liposomes, micelles, vesicles, dendritic polymers, nanoparticles, liquid crystals, microspheres, Implants etc., are used which have significant advantages and few limitations [4,20,24-26] (Figure 1).

*Corresponding author: Vijaya Shanti Bheemidi, Department of Biotechnology, Nottingham Trent University, Nottingham, United Kingdom

Received November 07, 2011; Accepted December 12, 2011; Published December 14, 2011

Citation: Vijaya Shanti B, Mrudula T, Pavan Kumar V (2011) An Imperative Note on Novel Drug Delivery Systems. J Nanomedic Nanotechnol 2:125. doi:10.4172/21577439.1000125

Copyright: ( 2011 Vijaya Shanti B, et al. This is an open-access article distributed under the terms of the Creative Commons Attribution License, which permits unrestricted use, distribution, and reproduction in any medium, provided the original author and source are credited. 


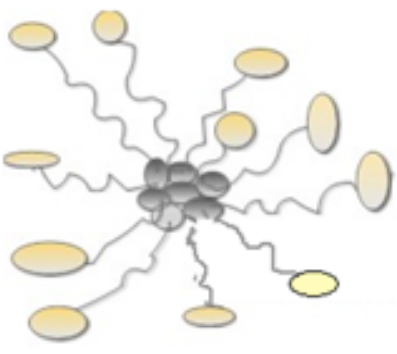

polymer micelles

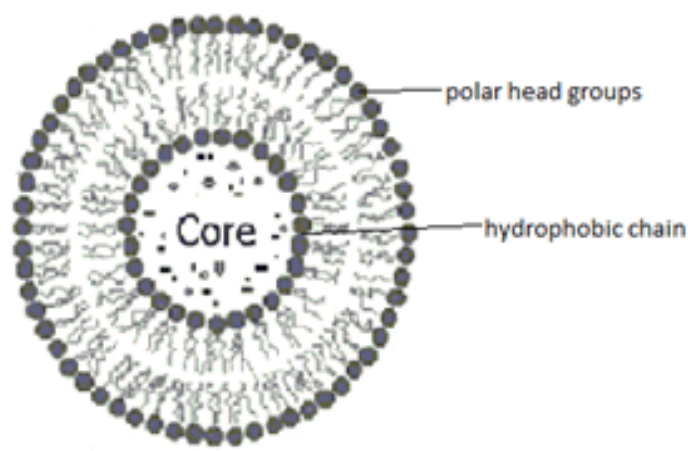

Liposomes

Figure 1: Drug Carriers

Liposomes: Liposomes are colloidal, biodegradable and spherical vesicles whose size varies from low micrometres range to tens of micrometres. They consist of a bilayer membrane entrapping an aqueous core. The membranes of liposomes are usually derived from phospholipids with mixed lipid chains and head groups or pure synthetic lipids with defined acyl chains and head groups. The drugs can be either entrapped at bilayer interface, in aqueous volume or in phospholipids bilayer [27]. Liposomes which are formed from phospholipids are mostly used to modify the pharmacokinetic profile of drugs, enzymes etc. This particular drug carrier is very advantageous in enhancing the therapeutic effect of anti-cancer agents through increasing drug concentration levels in tumour cells and decreasing the exposure to normal cells [28-29]. Liposomes play an important role in solubility enhancement, bioavailability, targeting sites and prolonged release of drug [30,31].

Microspheres: There are various drug delivery systems to deliver a drug to target site in a sustained controlled release fashion. One of the methods is using microspheres as drug carriers. These are produced from solid polymer matrices for intravenous and intra-arterial targeted drug delivery systems. Microspheres are spherical in shape and size varies from $1-300 \mu \mathrm{m}$. There are different kinds of polymers which are used for fabrication of microspheres are albumin, starch, gelatin, dextran, polypropylene etc. The administration of drug mediated by these microspheres is controlled by degradation and dissolution of matrix. The drug delivery is also affected by polymer concentration and type, size of matrix. There are various types of methods to produce these micro particulate systems such as evaporation technique, cross linking and high pressure homogenization technique. The specific advantages of these micro particulate systems are they can be injected or ingested and also they produce sustained release action and site specific delivery $[21,32,33]$.

Nano-particles: Nanoparticles are sub-micron sized particles having size of 10 to $200 \mathrm{~nm}$ are in the solid state either in amorphous or crystalline form [34-37]. The nanoparticles are widely used as carriers due to their stability and long term storage. They can encapsulate or adsorb the drug and help in protecting it from chemical and enzymatic degradation [38-42]. Nanoparticles include nanocapsules and nanospheres. The nanocapsules are vesicular systems in which drug is restrained or enclosed in a cavity surrounded by polymeric membrane, where as the drug is uniformly spread in the nanosphere matrix systems. The nanoparticles are very efficient in delivering both hydrophilic and hydrophobic drugs [43-48]. In the recent years the biodegradable polymeric nanoparticles have gained a significant attention as potential drug carrier in the applications of targeted drug delivery system, controlled release of drugs and as an efficient carrier of DNA in gene therapy and also capable to administrate proteins, peptides and genes through pre-oral route $[4,30,49-56]$.

Polymeric micelle formulations: The polymeric micelles consists of good pharmaceutical properties and are easily controllable. They are the excellent drug carriers which contains inner hydrophobic core and outer hydrophilic corona [57-60]. The inner core is capable of solubilizing lipohilic substances and it is stabilized by hydrophilic polymer chains which are towards aqeous environment. The outer corona acts as a interface between inner core and aqueous environment $[30,61]$

Implants: Implants are the polymeric devices which are used for the sustained drug release or to target high drug concentrations to the surrounding area of target tissue. These are usually applied when chronic therapy is indicated in situations like chemical castration in prostate cancer treatment, in hormones replacement. The Implants are highly viscous liquids or semisolid formulations which are directly placed in the body fluids, injected or fabricated with biodegradable polymers. Duros', Zoladex are the Implants used for long term delivery of proteins $[4,21,30]$.

\section{Drug Delivery Technologies/ Administration Routes}

The main aim of the drug delivery systems is to liberate the drug sat the right time in a right amount of concentration at a specified targeted site. The purpose of delivering drugs to patients in an efficient manner with fewer side effects encouraged pharmaceutical industries to develop various novel drug delivery technologies with enhanced site specificity, efficacy and profitability [5]. The various drug technologies include:

\section{OCRS}

Oral ingestion is a very traditional way of drug delivery system where effectively achieved local and systemic effects. The development of oral controlled release formulations is to be difficult challenge to the industries because of various gastrointestinal environments [6263]. Among the numerous platform technologies the matrix type drug delivery system was interesting option. One of the new techniques developed in oral drug delivery is to make gastroretentive platforms 
for long hours (8-24 hr) delivery of drugs [64]. This technology is beneficial for the drugs which are poorly absorbed in gastro intestinal tract. Oral delver of protein and peptide drugs is the most research activity performed. Emisphere technologies introduced the drug delivery through macromolecules where the carrier molecules are used to deliver the drugs. [5,21]

\section{Pulmonary delivery system}

Pulmonary delivery systems are primarily used for treatment of respiratory diseases. Recently this method is also used for administrating the drugs to systemic circulation by utilizing lung's natural capability to transfer molecules in to blood stream. This method is known as non-invasive which is used as alternative to painful injections. This delivery system provides an opportunity for enhanced and innovative delivery system, good bioavailability and greater patient's compliance. The inhale therapeutic systems are effected in various different ways like via metered dose inhaler systems (MDI's), aerosols, solutions (nebulizers) and dry powder inhaler systems (DPI's) [5,21]. In MDI's the drug is present in the form of solutions or suspension of fine particles in a pressurized liquefied propellant and drug is released through an orifice from metering valve. Recently the industries designed a technology to deliver peptides, proteins and large molecules in precise doses. The industries developed dry powder formulations that use glass stabilization technology, this extracts critical amount of water from proteins and helps to achieve glassy state. In this glassy state the proteins are grid locked and give long term storage, stability and sterility. Pulmospheres and pulmosols are also developed by companies through spray drying and supercritical fluid condensation respectively. Pulmospheres are hollow porous particles with high redispersibility, low density less than $0.1 \mathrm{gm} /$ nil helps in $68 \%$ pulmonary targeting. The developed novel pulmonary delivery system includes Oralin (Generex), AIR (Alkermes) and AERx (Aradigm) [4,21]

\section{Transdermal and Tropical delivery}

The administration of drugs through skin i.e., via transdermal routes in to the systemic circulation at a predetermined rate developed a significant interest during the last two decades [65]. Human skin is wonderful selective and highly effective barrier to chemical permeation. Specifically stratum corneum plays a major role in diffusion of small water soluble non-electrolytes in to the systemic circulation without any barrier hindrance. The drug flux is also maximized through other potential pathways like hair follicular route with sebaceous glands and via sweat ducts. The amount of active ingredient required for transdermal delivery system is considerably less when compared to oral systems. To increase the transdermal permeability of drugs the prodrugs or penetration enhancers are used, for these different electrically assisted techniques like ultrasound, electroporation, magnetophoresis, iontophoresis, and photomechanical waves are used [66]. The stratum corneum can also be modified by following some chemical enhancers, hydration procedures and removing the tissue by using micro needles [67]. There are also some needle-free injection devices which are operated by compressed gas a system that drives liquid or powder at very high speed and makes it to penetrate through skin for intra dermal, subcutaneous or intramuscular administration. Intraject, Biojector and Medijector systems are used for administration of liquids while solids are administrated through PowderJect's technology. In this technology the dry powder formulations of small solid particles are forced in to the target tissue layers. The drug particles are accelerated with supersonic speed within a helium gas jet inside the device. Due to microscopic size of drug particles, they enter into the cells without damaging the cell membranes. PowderJect is working on genetic vaccines in collaboration with GlaxoWellcome, and their hepatitis B prophylactic DNA vaccine has successfully completed clinical trials. This delivery system enhances bio availability with fewer side effects and is an easy application $[5,21,68]$.

\section{Hydrogels as drug delivery systems}

Hydrogels are three dimensional hydrophilic polymer networks which can absorb huge amounts of water and other biological fluids. The networks consist of homopolymers or copolymers and they are insoluble because of physical crosslinks like crystallites or entanglements and chemical cross links such as junctions and tie points. Hydrogels possess thermodynamic compatibility with water due to which they swell in aqueous media. They acts as carriers in swellable or swellingcontrolled release devices or regulates drug release in controlled release systems. Hydrogels are a stimuli-sensitive and enviro-intelligent system that controls the drug release according to the temperature, $\mathrm{pH}$, electrical field, ionic strength and specific analyte concentrations. Hydrogels as delivery systems can be promising when they combined with the molecular imprinting technology $[10,30]$.

The molecular imprinting technique contains huge potential of producing satisfactory drug dosage forms. It involves a prepolymerization complex formation between template and functional monomers or oligomers by covalent or non-covalent chemistry. Once the complex formed polymerization occurs with the help of cross linking monomers and appropriate solvent which controls the overall morphology and structure. When the template is removed the result produced is hetero polymer matrix with specific recognition elements for template molecule. The MIP-based drug delivery systems possess a i) rate programmed drug deliver where the drug diffusion from the system follows a specific rate profile. ii) feedback-regulated drug delivery where the concentration of a triggering agent regulated the drug release. Iii) activation- modulated drug delivery where the drug release is controlled by physical, chemical or biochemical processes. It can be foreseen that in the next coming years a considerable change evolves in this drug delivery system [4].

\section{Colon specific delivery}

Colon directed delivery is highly suitable for treatment of various bowel diseases like ulcerativecolitis, Crohn's disease, amebiosis, and colonic cancer. I $\mathrm{n}$ the past few years' considerable interest on colon targeting drugs because of their reduced proteolytic activity in the colon which is very much advantageous for the drugs like peptides and proteins, that are enzymatically degraded in the small intestine [69]. There are many colon specific dosage forms were developed in past few years including hydrogel matrix, pro drugs and coated dosage forms. These coated dosage forms are mainly based on the two factors, $\mathrm{pH}$ controlled release coatings and time controlled release coatings. The $\mathrm{pH}$ - controlled release coatings are generally insoluble at $\mathrm{pH}$ of the stomach and dissolves in lumen of the small intestine. The thickness of drug coating is increased and a pH-time controlled release system of polymer dissolution helps in achieving the drug release in colon. In time-controlled release coating the lag time depends upon the thickness of drug coating there by the drug release can be achieved by changes in osmotic pressure or disrupting the drug coating by swelling the core $[5,10,70]$.

\section{Taste masking}

Oral drugs often reveal a bitter and unpleasant taste. In order to 
improve the flavour in these drugs various methods for taste masking has developed. They are like particle coating, compounding the drugs with cyclodextrins or resins, use of microcapsules, etc [71-73]. In chewable tablets a mild drug complex is spread on a gum base where the drug is released from the dosage form by physical disruption through chewing and chemical disruption from interaction between the drug material and oral cavity. Drug coating technique acts as a physical barrier between the drug and the taste receptors present in mouth. [5]

\section{Vaginal or rectal drug delivery}

The vagina has been detected as a highly suitable site for local and systemic drug delivery. This route has many advantages like reduction in hepatic and gastro intestinal side effects, avoid of gut metabolism and local targeting of drugs to reproductive organs. The formulations and vaginal administered agents are mainly developed for dual prophylaxis that is for both contraception and protection against infections, AIDS and other sexually transmitted diseases [5]

\section{Future Directions and Conclusions}

As discussed in this article there are numerous drug delivery technologies such as oral, pulmonary, Transdermal, colon, vaginal, etc to deliver the drugs in an efficient manner. Recently biotechnological companies producing many more protein and peptide based drugs by sequencing the human genome. It is estimated in next 10 to 20 years more than half of the drugs are replaced by protein based drugs especially $80 \%$ of them are antibodies. The drugs like proteins, peptides, carbohydrates, oligo-nucleotides and nucleic acids in the form of DNA usually cannot be delivered through conventional routes because of their large molecular size, rapid degrading ability, and limited ability to cross cell membranes [4,5]. For such drugs injections may be only route, which presents the industries a new challenge for developing new drug administration routes. Gene therapy is also one of the exciting sector in biotech companies going to be involved in drug delivery technologies. This therapy includes genetically engineered proteins. So far the industries have come in a long way and wish to continue the growth at impressive rate in drug delivery systems. Tomorrow's drugs definitely will be more challenging in terms of the development of delivery systems, and pharmaceutical scientists will have to be ready for a difficult task ahead $[10,30]$

\section{References}

1. These N (2005) Development Of A Novel Drug Delivery System Based On Polymeric, Thermoresponsive, Hydrogel Nanoparticles

2. http://www.aavpt.org/symposia/documents/McGinity70-78.pdf

3. Hu Y, Liang S, Zhu J, Qin G, Liu Q, et al. (2011) Factors Associated with Recent Risky Drug Use and Sexual Behaviors among Drug Users in Southwestern China. J AIDS Clinic Res 2:120.

4. Vikas K, Arvind S, Ashish S, Gourav J, Vipasha D (2011) Recent Advances In Ndds (Novel Drug Delivery System) For Delivery Of Anti- Hypertensive Drugs. Int J Drug Dev \& Res 3: 252-259

5. Rajan KV, Sanjay G (2001) "Current Status of Drug Delivery Technologies and Future Directions" Pharmaceutical Technology On-Line 25: 1-14

6. Wee T, Jenssen H (2009) Influenza Drugs - Current Standards and Novel Alternatives. J Antivir Antiretrovir 1: 001-010.

7. Ahmad M, Madni AU, Usman M (2009) In-Vitro Release and Pharmacokinetics of Anti-tubercle Drug Ethionamide in Healthy Male Subjects. J Bioanal Biomed 1: 046-049.

8. Roiha IS, Otterlei E, Samuelsen OB (2010) Bioencapsulation of Florfenicol in Brine Shrimp, Artemia Franciscana, Nauplii. J Bioanal Biomed 2: 060-064.
9. Najib NB, Salem I, Hasan R, Idkaidek NM (2009) Effect of Truncated AUC Method on Drug Bioequivalence in Humans. J Bioequiv Availab 1: 112-114.

10. Mahapatra L, Sahoo GR, Panda MK, Parija S (2009) Pharmacokinetic Profile of Nimesulide in Bovine Calves. J Bioequiv Availab 1: 121-026.

11. Griffi ni P, James AD, Roberts AD, Pellegatti M (2010) Metabolites in Safety Testing: Issues and Approaches to the Safety Evaluation of Human Metabolites in a Drug that is Extensively Metabolized. J Drug Metabol Toxicol 1:102.

12. Ghemtio L, Smaïl-tabbone M, Djikeng A, Devignes MD, Keminse L, et al (2011) HIV-PDI: A Protein-Drug Interaction Resource for Structural Analyses of HIV Drug Resistance: 1. Concepts and Associated Database. J Health Med Informat 2:104.

13. Arun B (2009) Challenges in Drug discovery: Can We Improve Drug Development. J Bioanal Biomed 1: 050-053

14. Essawy AE, Helal SF, El- Zoheiry AH, El- Bardan EM (2010) Hepatotoxicity Induced by Antifungal Drug Fluconazole in the Toads (Bufo Regularis). J Drug Metabol Toxicol 1:106

15. Ghemtio L, Souchet M, Djikeng A, Keminse L, Kelbert P, et al. (2011) HIV PDI: A Protein Drug Interaction Resource for Structural Analyses of HIV Drug Resistance: 2. Examples of Use and Proof-of-Concept. J Health Med Informat 2:105

16. Ravali R, Phaneendra M, Bhanu Jyothi K, Ramya Santhoshi L, Sushma K (2011) Recent Trends in Analytical Techniques for the Development of Pharmaceutical Drugs. J Bioanal Biomed S12.

17. Uchiumi F, Oyama T, Ozaki K, Tanuma SI (2011) Development of Novel Antiaging Drugs. Pharm Anal Acta 2:106e.

18. Yazigi A, Abou-Zeid H, Haddad F, Madi-Jebara S, Hayek G, et al. (2010) Correlation between Central Venous - Arterial Carbon Dioxide Tension Gradient and Oxygen Delivery Changes Following Fluid Therapy. J Anesthe Clinic Res 1:110.

19. Najib NM, Salem I, Idkaidek NM (2009) Effect of Replicate Design on Drug Variability and Bioequivalence in Humans. J Bioanal Biomed 1: 014-016.

20. Barbe C, Bartlett J, Kong L, Finnie K, Lin HQ, et al. (2004) Silica Particles: A Novel Drug-Delivery System. Advanced Materials 16: 1959-1966.

21. Bajaj A, Desai M (2006) Challenges and strategies in novel drug delivery technologies. Pharma Times 38: 12-16

22. De Caro V, Giandalia G, Siragusa MG, Campisi G, Giannola LI (2009) Galantamine Delivery on Buccal Mucosa: Permeation Enhancement and Design of Matrix Tablets. J Bioequiv Availab 1: 127-134.

23. Shakeel F, Ramadan W, Shafiq S (2009) Solubility and Dissolution Improvement of Aceclofenac using Different Nanocarriers. J Bioequiv Availab 1: 039-043

24. Nanjwade BK, Parikh KA, Deshmukh RV, Nanjwade VK, Gaikwad KR, et al (2011) Development and Evaluation of Intranasal Mucoadhesiv Microspheres of Neostigmine Bromide. Pharm Anal Acta 2:118.

25. Plassat V, Renoir JM, Autret G, Marsaud V, Ménager C, et al. (2011) Systemic Magnetic Targeting of Pure-Antiestrogen-Loaded Superparamagnetic Nanovesicles for Effective Therapy of Hormone-Dependent Breast Cancers. J Bioanal Biomed S2: 001

26. Nanjwade BK, Derkar GK, Bechra HM, Nanjwade VK, Manvi FV (2011) Design and Characterization of Nanocrystals of Lovastatin for Solubility and Dissolution Enhancement. J Nanomedic Nanotechnol 2:107

27. Afergan E, Najajreh Y, Gutman D, Epstein H, Elmalak O, et al. (2010) 31P-NMR and Differential Scanning Calorimetry Studies for Determining Vesicle's Drug Physical State and Fraction in Alendronate Liposomes. J Bioanal Biomed 2 125-131.

28. Arpke RW, Cheng PW (2011) Characterization of Human Serum AlbuminFacilitated Lipofection Gene Delivery Strategy. J Cell Sci Ther 2:108.

29. Vaghasia N, Federman N (2011) Liposomes for Targeting Cancer: One Step Closer to the Holy Grail of Cancer Therapeutics? J Nanomedic Biotherapeu Discover 1:105e

30. Ashwani Goyal, Sandeep Kumar, Manju Nagpal , Inderbir Singh, Sandeep 
Citation: Vijaya Shanti B, Mrudula T, Pavan Kumar V (2011) An Imperative Note on Novel Drug Delivery Systems. J Nanomedic Nanotechnol 2:125. doi:10.4172/2157-7439.1000125

Arora, et al. (2011) Potential of Novel Drug Delivery Systems for Herbal Drugs. Ind J Pharm Edu Res 45: 225-235.

31. Dibirdik I, Yiv S, Qazi S, Uckun FM (2010) In vivo Anti-Cancer Activity of a Liposomal Nanoparticle Construct of Multifunctional Tyrosine Kinase Inhibitor 4-(4'-Hydroxyphenyl)-Amino-6,7-Dimethoxyquinazoline. J Nanomedic Nanotechnolo 1: 101

32. Venkatesan P, Manavalan R, Valliappan K (2009) Microencapsulation: A vital technique in novel drug delivery system. J Pharm Sci \& Res 1: 26-35

33. Nanjwade BK, Patel DJ, Parikh KA, Nanjwade VK, Manvi FV (2011) Development and Characterization of Solid-Lipid Microparticles of Highly Insoluble Drug Sirolimus. J Bioequiv Availab 3: 011-015.

34. Vijaya Shanti B, Mrudula T, Naga Deepth CH, Sree Venkateshwarlu Y (2011) Novel Applications of Nanotechnology in Life Sciences. J Bioanal Biomed S11.

35. Lukianova-Hleb EY, Oginsky AO, Shenefelt DL, Drezek RA, Hafner JH, et al. (2011) Rainbow Plasmonic Nanobubbles: Synergistic Activation of Gold Nanoparticle Clusters. J Nanomedic Nanotechnol 2:104

36. Menaa B (2011) The Importance of Nanotechnology in Biomedical Sciences. J Biotechnol Biomaterial 1:105e.

37. Zheng J, Clogston JD, Patri AK, Dobrovolskaia MA, McNeil SE (2011) Sterilization of Silver Nanoparticles Using Standard Gamma Irradiation Procedure Affects Particle Integrity and Biocompatibility. J Nanomedic Nanotechnol S5: 001.

38. Rosarin FS, Mirunalini S (2011) Nobel Metallic Nanoparticles with Novel Biomedical Properties. J Bioanal Biomed 3: 085-091.

39. Mehrotra A, Nagarwal RC, Pandit JK (2010) Fabrication of Lomustine Loaded Chitosan Nanoparticles by Spray Drying and in Vitro Cytostatic Activity on Human Lung Cancer Cell Line L132. J Nanomedic Nanotechnolo 1: 103

40. Nguyen KT (2011) Targeted Nanoparticles for Cancer Therapy: Promises and Challenges. J Nanomedic Nanotechnol 2: 103e.

41. Amirthalingam T, Kalirajan J, Chockalingam A (2011) Use of Silica-Gold Core Shell Structured Nanoparticles for Targeted Drug Delivery System. J Nanomedic Nanotechnol 2:119.

42. Yun Y, Conforti L, Muganda P, Sankar J (2011) Nanomedicine-based Synthetic Biology. J Nanomedic Biotherapeu Discover 1: 102e.

43. Knight LC, Romano JE, Krynska B, Faro S, Mohamed FB, et al. (2010) Binding and Internalization of Iron Oxide Nanoparticles Targeted To Nuclear Oncoprotein. J Mol Biomark Diagn 1:102.

44. Khan DR (2010) The Use of Nanocarriers for Drug Delivery in Cancer Therapy. J Cancer Sci Ther 2: 058-062.

45. Li Y, Hu M, Qi B, Wang X, Du Y (2011) Preparation and Characterization of Biocompatible Quaternized Chitosan Nanoparticles Encapsulating CdS Quantum Dots. J Biotechnol Biomaterial 1: 108.

46. Muro S (2011) Efficient and Safe Intra-cellular Transport of Targeted Nanomedicines: are we there Yet? J Nanomedic Biotherapeu Discover 1:106e.

47. Tsigelny IF, Simberg D (2011) Has the Time for In silico Design of Nanomedicines Finally Arrived? J Nanomedic Biotherapeu Discover 1:104e.

48. Nguyen KT (2011) Targeted Nanoparticles for Cancer Therapy: Promises and Challenges. J Nanomedic Nanotechnol 2: $103 \mathrm{e}$.

49. Caraglia M, Rosa GD, Abbruzzese A, Leonetti C (2011) Nanotechnologies: New Opportunities for Old Drugs. The Case of Aminobisphosphonates. J Nanomedic Biotherapeu Discover 1:103e.

50. Douroumis D (2011) Mesoporous silica Nanoparticles as Drug Delivery System. J Nanomedic Nanotechnol 2:102e

51. Patil A, Chirmade UN, Trivedi V, Lamprou DA, Urquhart A, et al. (2011) Encapsulation of Water Insoluble Drugs in Mesoporous Silica Nanoparticles using Supercritical Carbon Dioxide. J Nanomedic Nanotechnol 2:111

52. Thomas S, Waterman P, Chen S, Marinelli B, Seaman M, et al. (2011) Development of Secreted Protein and Acidic and Rich in Cysteine (SPARC) Targeted Nanoparticles for the Prognostic Molecular Imaging of Metastatic Prostate Cancer. J Nanomedic Nanotechnol 2:112
53. Shih MF, Wu CH, Cherng JY (2011) Bioeffects of Transient and LowIntensity Ultrasound on Nanoparticles for a Safe and Efficient DNA Delivery. J Nanomedic Nanotechnol S3:001

54. Saboktakin MR, Tabatabaie RM, Maharramov A, Ramazanov MA (2011) Synthesis and Characterization of Biodegradable Thiolated Chitosan Nanoparticles as Targeted Drug Delivery System. J Nanomedic Nanotechnol S4:001.

55. Rosarin FS, Mirunalini S (2011) Nobel Metallic Nanoparticles with Novel Biomedical Properties. J Bioanal Biomed 3: 085-091

56. Kanwar JR, Zhou SF, Gurudevan S, Barrow CJ, Kanwar RK (2011) Toll Like Receptors Play a Role in General Immunity, Eye Infection and Inflammation: TIrs for Nanodelivery. J Clin Cell Immunol 2: 114.

57. Anwunobi AP, Emeje MO (2011) Recent Application of Natural Polymers in Nanodrug Delivery. J Nanomedic Nanotechnol S4: 002

58. Eshita Y, Higashihara J, Onishi M, Mizuno M, Yoshida J, et al. (2011) Mechanism of the Introduction of Exogenous Genes into Cultured Cells Using DEAE-Dextran-MMA Graft Copolymer as a Non-Viral Gene Carrier. II. Its Thixotropy Property. J Nanomedic Nanotechnol 2:105.

59. Sun CZ, Lu CT, Zhao YZ, Guo P, Tian JL, et al. (2011) Characterization of the Doxorubicin-Pluronic F68 Conjugate Micelles and Their Effect on Doxorubicin Resistant Human Erythroleukemic Cancer Cells. J Nanomedic Nanotechnol 2 114.

60. Sun CZ, Lu CT, Zhao YZ, Guo P, Tian JL, et al. (2011) Characterization of the Doxorubicin-Pluronic F68 Conjugate Micelles and Their Effect on Doxorubicin Resistant Human Erythroleukemic Cancer Cells. J Nanomedic Nanotechnol $2: 114$.

61. Nasongkla N, Bey E, Ren J, Ai H, Khemtong C, et al (2006) Multifunctional Polymeric Micelles as Cancer-Targeted, MRI-Ultrasensitive Drug Delivery Systems. Nano lett 6: 2427-2430

62. Elgindy N, Elkhodairy K, Molokhia A, ElZoghby A (2011) Biopolymeric Nanoparticles for Oral Protein Delivery: Design and In Vitro Evaluation. J Nanomedic Nanotechnol 2:110

63. Krishnaiah YSR (2010) Pharmaceutical Technologies for Enhancing Oral Bioavailability of Poorly Soluble Drugs. J Bioequiv Availab 2: 028-036

64. Dang Q, Reddy KR, Kasibthatla SR, Jiang T, Taplin F, et al. (2010) Discovery of Phosphonic Acid-Containing Desaminobenzimidazoles as Fructose 1,6-Bisphosphatase Inhibitors that are Suitable for Oral Delivery via Prodrugs. J Diabetes Metab 1:105

65. Peramo A (2010) Novel Double Lumen Catheter for Drug Delivery at the SkinCatheter Interface. J Tissue Sci Eng 1:102.

66. Yoshiba S, Okabe H, Ishizuka H (2011) Pharmacokinetics of Laninamivir after a Single Administration of its Prodrug, Laninamivir Octanoate, a Long-Acting Neuraminidase Inhibitor, Using an Easy-to-Use Inhaler in Healthy Volunteers. J Bioequiv Availab 3: 001-004.

67. Elshafeey AH, Hamza YE, Amin SY, Akhlaghi F, Zia H (2011) Enhanced Bioavailability of Fenoterol Transdermal Systems in Rabbits. J Bioequiv Availab 3: 097-100.

68. Barry BW (2001) Novel mechanisms and devices to enable successful transdermal drug delivery. Eur J Pharm Sci 14: 101-114

69. Zhao Y, Haney MJ, Mahajan V, Reiner BC, Dunaevsky A, et al. (2011) Active Targeted Macrophage-mediated Delivery of Catalase to Affected Brain Regions in Models of Parkinson's Disease. J Nanomedic Nanotechnol S4:003.

70. Philip AK, Philip B (2010) Colon Targeted Drug Delivery Systems: A Review on Primary and Novel Approaches. OMJ 25: 70-78.

71. Chatsiricharoenkul S, Niyomnaitham S, Pongnarin P, Sathirakul K Kongpatanakul S (2011) Bioequivalence Study of $10 \mathrm{mg}$ Olanzapine Tablets in Healthy Thai Volunteers. J Bioequiv Availab 3: 082-085.

72. Nayak AK, Maji R, Das B (2010) Gastroretentive drug delivery systems: a review. Asian Journal of Pharmaceutical and Clinical Research 3: 2-10

73. Roiha IS, Otterlei E, Samuelsen OB (2010) Bioencapsulation of Florfenicol in Brine Shrimp, Artemia Franciscana, Nauplii. J Bioanal Biomed 2: 060-064 